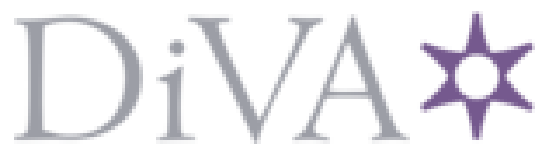

http://www.diva-portal.org

This is the published version of a paper published in Environmental Science and Technology.

Citation for the original published paper (version of record):

Du, X., Yuan, B., Zhou, Y., Zheng, Z., Wu, Y. et al. (2019)

Tissue-Specific Accumulation, Sexual Difference, and Maternal Transfer of Chlorinated

Paraffins in Black-Spotted Frogs

Environmental Science and Technology, 53(9): 4739-4746

https://doi.org/10.1021/acs.est.8bo6350

Access to the published version may require subscription.

N.B. When citing this work, cite the original published paper.

Permanent link to this version:

http://urn.kb.se/resolve?urn=urn:nbn:se:umu:diva-1596o8 


\title{
Tissue-Specific Accumulation, Sexual Difference, and Maternal Transfer of Chlorinated Paraffins in Black-Spotted Frogs
}

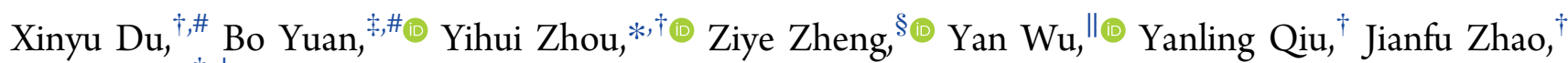
and Ge Yin ${ }^{\ddagger} \perp$

\author{
${ }^{\dagger}$ State Key Laboratory of Pollution Control and Resource Reuse, College of Environmental Science and Engineering, Tongji \\ University, Shanghai 200092, P. R. China \\ ${ }^{\ddagger}$ Department of Environmental Science and Analytical Chemistry, Stockholm University, SE-10691 Stockholm, Sweden \\ ${ }^{\S}$ Department of Chemistry, Umeå University, SE-901 87 Umeå, Sweden \\ "School of Public and Environmental Affairs, Indiana University, Bloomington, Indiana 47405, United States \\ ${ }^{\perp}$ Shimadzu (China) Company, Limited, Shanghai 200233, P. R. China
}

Supporting Information

ABSTRACT: The restriction on usage of short-chain chlorinated paraffins (SCCPs) under Stockholm Convention may promote the production and application of medium chain chlorinated paraffins (MCCPs) and long chain chlorinated paraffins (LCCPs) as substitutes. This study focused on the tissue-specific exposure to SCCPs, MCCPs, and LCCPs in black-spotted frog, a prevalent amphibian species in the Yangtze River Delta, China. The total CP concentrations in frog liver, muscle, and egg samples ranged of 35-1200, 6.397, and 6.8-300 $\mathrm{ng} / \mathrm{g}$ wet weight (ww), respectively. Livers and eggs contained primary SCCPs (on average $78 \%$ ) while MCCPs (43\%) together with SCCPs (41\%) were dominant in muscles. A significantly negative correlation was observed between hepatosomatic index and CPs concentration in liver $(p<$ 0.01 ), indicating that $\mathrm{CP}$ exposure may lower survival rates of frogs by suppressing the energy storage in liver. Additionally, maternal transfer, an important uptake pathway for CPs, was evaluated for the first time by calculating the ratios of CP levels in eggs to those in their paired liver tissues. The ratio of egg to liver for CP congener groups raised with the increasing of log $K_{\mathrm{ow}}$ values, indicating mother to egg transport of CPs was related to the lipophilicity of the chemicals.

\section{INTRODUCTION}

Chlorinated paraffins (CPs), also known as polychlorinated $n$ alkanes, are as suite of large production volume chemicals that have been widely used as lubricants, flame retardants, and plasticizers for decades. ${ }^{1,2}$ By using a simple production process of direct radical chlorination of $n$-alkane feedstocks, ${ }^{3}$ the annual production amount of CPs in China reached 1.05 million tons in 2013, making China the largest producer, consumer, and exporter worldwide. ${ }^{4}$ Due to their large-scale and heavy usage, CPs have been detected in a variety of environment compartments around world. ${ }^{5-8}$ According to the carbon chain length, CPs are commonly classified into shortchain (SCCPs, $\mathrm{C}_{10-13}$ ), medium-chain (MCCPs, $\mathrm{C}_{14-17}$ ), and long-chain CPs (LCCPs, $\mathrm{C}_{\geq 18}$ ). Of these three CPs groups, SCCPs have attracted considerable attention due to their high aquatic and mammalian toxicity, ${ }^{9}$ bioaccumulation potential, $^{10,11}$ and long-range transport tendency. ${ }^{12,13}$ In April 2017, SCCPs have been officially listed as Persistent Organic Pollutants (POPs) under the Stockholm Convention. ${ }^{14}$ As alternatives to SCCPs, MCCPs and LCCPs are expected to have more production and usage in the future. ${ }^{15,16}$ Recent research pointed out that MCCPs and LCCPs may be equally or even more bioaccumulative than SCCPs. ${ }^{17}$ However, studies on the occurrence and fate of these two groups are still limited, particularly for LCCPs. ${ }^{18}$

In the past few decades, chemical contamination has been considered as one of the major factors causing the global population decline of amphibians. ${ }^{19}$ The amphibians are chemical sensitive vertebrates due to their unique physiological characteristics, i.e., highly permeable skin, low metabolic rate, and biphasic life history. ${ }^{20}$ However, it has been demonstrated that only $3.8 \%$ of the vertebrate ecotoxicological research (152 for 17375 citations) was conducted on amphibians. ${ }^{20}$ Previous studies on the occurrence and fate of CPs in biotas primarily focused on fish, ${ }^{7,21,22}$ birds (mostly piscivorous), ${ }^{23-25}$ reptiles, ${ }^{25,26}$ and mammals. ${ }^{27-29}$ To our knowledge, to date there is only one paper quantified the SCCPs level of one frog

Received: November 14, 2018

Revised: $\quad$ March 23, 2019

Accepted: April 12, 2019

Published: April 12, 2019 
Table 1. Concentrations (ng/g ww) of SCCPs, MCCPs, and LCCPs in Liver, Egg, and Muscle Samples of Black-Spotted Frogs from Yangtze River Delta

\begin{tabular}{|c|c|c|c|c|c|c|c|}
\hline tissue & gender & $N$ & lipid (\%) & $\mathrm{Cl} \%$ & SCCPs & MCCPs & LCCPs \\
\hline liver & female & 12 & $25.38 \pm 6.40^{a}$ & $53.5 \pm 0.2$ & $360 \pm 240(190-910)^{b}$ & $69 \pm 47(31-190)$ & $8.5 \pm 6.9(<\mathrm{LOQ}-26)$ \\
\hline liver & male & 12 & $18.77 \pm 8.46$ & $53.6 \pm 0.4$ & $320 \pm 300(28-910)$ & $68 \pm 59(5.5-180)$ & $28 \pm 34\left(N^{c}-110\right)$ \\
\hline egg & / & 12 & $9.87 \pm 2.26$ & $53.9 \pm 0.6$ & $62 \pm 64(\mathrm{ND}-220)$ & $16 \pm 14(<$ LOQ -52$)$ & $2.9 \pm 5.7(\mathrm{ND}-20)$ \\
\hline muscle & female & $3^{d}$ & $0.53 \pm 0.03$ & $52.8 \pm 0.6$ & $6.9 \pm 4.8$ & $5.0 \pm 3.0$ & $2.6 \pm 2.1$ \\
\hline muscle & male & $2^{d}$ & $0.57-0.66$ & $52.2-52.4$ & $14-31$ & $25-50$ & $7.6-16$ \\
\hline
\end{tabular}

sample. $^{30}$ Amphibian exposure to CPs in the environment remains limited studied.

It is of great importance to understand the chemicalassociated embryotic toxicity to oviparous organisms since early life stages of these organisms are often more vulnerable to hazardous contaminants compared with adult life stages. ${ }^{31}$ Toxicity tests have confirmed that SCCPs could decrease the survival rate of zebrafish larvae, induce developmental malformations, and reduce embryos growth of Xenopus laevis frog embryos. ${ }^{32,33}$ The maternal transfer of lipophilic compound from parent to egg is considered as the major exposure pathway for embryos. ${ }^{34}$ Maternal transfers have been observed for trace elements, ${ }^{34}$ organochlorine pesticide (OCPs), polychlorinated dibenzo-p-dioxins and dibenzofurans (PCDD/Fs), coplanar polychlorinated biphenyls (PCBs), ${ }^{35}$ and polybrominated diphenyl ethers (PBDEs) ${ }^{36}$ in frogs, but maternal transfer of CPs in amphibians remained scarcely studied.

Our recent work reported considerable levels of SCCPs, MCCPs, and LCCPs in bird, reptile, fish, and mammal species from paddy fields in the Yangtze River Delta (YRD) ${ }^{25}$ The black-spotted frog (Pelophylax nigromaculatus) is a widespread amphibian species commonly found in YRD. Considering the black-spotted frogs from the paddy fields in YRD are likely to have similar CPs exposure pathway with species we previously studied, it is conceivable that the frogs may also face the threat of high CPs exposure. In the present study, wild black-spotted frogs were collected from paddy fields in YRD. SCCPs, MCCPs, and LCCPs were determined in frog liver, muscle, and eggs using atmospheric-pressure chemical ionization quadrupole time-of-flight mass spectrometer (APCI-QTOFMS) method. Our goals were to (a) investigate the levels and congener group patterns of CPs in different frog tissues, (b) explore the relationships between CPs exposure and physiological parameters, and (c) evaluate sexual differences of CP accumulation and CPs' maternal transfer behaviors.

\section{METHODS AND MATERIALS}

Sampling. A total of 69 black-spotted frogs (Pelophylax nigromaculatus) were collected from paddy field in YRD, China. Detailed information on sampling area was provided in our previous studies. ${ }^{25,37}$ Sex, snout-vent length (SVL), and body weight of the frogs were recorded before dissection. Liver and muscle samples were carefully dissected from frog individuals. Unfertilized frog egg samples were collected from the ovaries of maternal frogs. CPs in the muscles of individual frogs were difficult to be measured due to very low lipid content of muscle (Table 1). In order to have enough material for CP analysis, the muscle samples were randomly pooled based on sex (45 individuals in 5 pools, 3 for female frogs and 2 for male frogs). Among 69 individuals, 12 male frog liver samples, 12 female liver samples together with 12 paired frog egg samples were chosen to investigate the CP burdens in frog liver and eggs. The muscle samples were freeze-dried and then homogenized into a powder in liquid nitrogen. Dried muscle samples, fresh liver, and egg samples were stored at $-20{ }^{\circ} \mathrm{C}$ prior to $\mathrm{CP}$ analysis.

Standards and Reagent. ${ }^{13} \mathrm{C}_{10}-1,5,5,6,6,10$-hexachlorodecane $\left({ }^{13} \mathrm{C}-\mathrm{HCD}\right)$ was purchased from Cambridge Isotope Laboratories (Andover, MA U.S.A.). Dechlorane 603 was purchased from Wellington Laboratories (Guelph, Ontario, Canada). CP reference standards and commercial products are given in Table S1 of the Supporting Information, SI. All solvents and acids used were of the highest commercially available quality. Silica gel (0.063-0.2 mm; Merck, Darmstadt, Germany) and anhydrous sodium sulfate (Sinopharm Chemical Reagent Co, Shanghai, China) were activated at $300{ }^{\circ} \mathrm{C}$ for $3 \mathrm{~h}$ prior to use.

Extraction and Clean Up. The extraction and cleanup of CPs was carried out according to our previous published method $^{25}$ with a minor modification for the extraction of liver and egg samples. In brief, approximately $2 \mathrm{~g}$ (dry weight) muscle sample spiked with an isotopically labeled surrogate standard ( ${ }^{13} \mathrm{C}-\mathrm{HCD} ; 15 \mathrm{ng}$ ) was Soxhlet extracted with 200 $\mathrm{mL}$ of dichloromethane/hexane $(1: 1, \mathrm{v} / \mathrm{v})$ for $24 \mathrm{~h}$. Approximately $2 \mathrm{~g}$ of egg samples (fresh weight) and whole liver tissues, mixed with $5 \mathrm{~g}$ anhydrous sodium sulfate, were subjected to the same Soxhlet extraction procedure. Lipids were determined gravimetrically, and then removed using concentrated sulfuric acid, followed by further cleanup using Pasteur pipet packed with acidic silica gel. CPs was separated on a deactivated $\left(3 \% \mathrm{H}_{2} \mathrm{O}\right)$ silica gel column. Two fractions, first with $25 \mathrm{~mL}$ hexane and second with $25 \mathrm{~mL}$ solvent mixture of hexane and dichloromethane $(50 / 50, \mathrm{v} / \mathrm{v})$ were eluted. The second fraction was collected, concentrated to 100 $\mu \mathrm{L}$, and fortified with a volumetric standard (Dechlorane 603; $5 \mathrm{ng}$ ) prior to the instrumental analysis.

CP Analysis. CPs were measured using APCI-QTOF-MS (QTOF Premier, Waters, Manchester, U.K.) operated in full scan mode $(m / z 250-1000)$. Instrumental parameters were in accordance with our previous studies, ${ }^{38,39}$ which enabled detection of CPs with a minimum of two chlorine atoms. The isotopically labeled CP standard $\left({ }^{13} \mathrm{C}-\mathrm{HCD}\right)$ was analyzed by gas chromatography-mass spectrometry (GC-MS) in NCI (negative ion chemical ionization) mode. ${ }^{40}$ This is because that target ions of ${ }^{13} \mathrm{C}-\mathrm{HCD}$ confounds some ions of native $\mathrm{C}_{11} \mathrm{Cl}_{6}$ using APCI-QTOF-MS, but ${ }^{13} \mathrm{C}-\mathrm{HCD}$ can be resolved as a single peak standing out from the humps of native $\mathrm{CPs}$ using GC-NCI-MS. ${ }^{41}$

$\mathrm{CP}$ congener groups from $\mathrm{C}_{10} \mathrm{H}_{19} \mathrm{Cl}_{3}$ to $\mathrm{C}_{31} \mathrm{H}_{52} \mathrm{Cl}_{12}\left(\mathrm{C}_{10-31}\right.$, $\mathrm{Cl}_{2-12}$ ) were screened in all the samples. Detailed $\mathrm{m} / z$ ratios are stated in Yuan et al. (2017). ${ }^{42}$ Since no $\mathrm{C}_{27}-\mathrm{C}_{31}$ CPs were identified, $\mathrm{C}_{10} \mathrm{H}_{19} \mathrm{Cl}_{3}$ to $\mathrm{C}_{26} \mathrm{H}_{52} \mathrm{Cl}_{12}\left(\mathrm{C}_{10-26}, \mathrm{Cl}_{2-12}\right)$ composed of a $\mathrm{CP}$ congener group pattern of a sample in this study. The 
quantification method developed by Bogdal et al. ${ }^{43}$ was used. The CP pattern of each sample was reconstructed from the patterns of $19 \mathrm{CP}$ products using a pattern-deconvolution algorithm. Thereafter the instrument response factors of SCCPs, MCCPs, and LCCPs in the sample were calculated according to relative contributions of individual $\mathrm{CP}$ products (Tables S4-S6). A brief description is given in Figure S1.

Quality Assurance/Quality Control. Three $C_{10}$ and one $C_{11}$ single-chain-length standards together with the other 15 mixed-chain-length standards and commercial mixtures were applied for CP quantitation. SCCPs in most samples were dominated by $\mathrm{C}_{10}$ and/or $\mathrm{C}_{11} \mathrm{CPs}$, which did not match any SCCP products $\left(\mathrm{C}_{11}\right.$ and/or $\mathrm{C}_{12}$ predominated) we have. Here, the use of the single-chain-length standards improved the performance of pattern-deconvolution (i.e., the goodness of fit $\mathrm{R}^{2} \geq 0.80$; Tables $\left.\mathrm{S} 2-\mathrm{S} 4\right) .{ }^{44}$ Such high $\mathrm{R}^{2}$ means that $\mathrm{CP}$ patterns in the samples were well-reconstructed in terms of the patterns of reference standards and commercial mixtures. ${ }^{45}$ Dechlorane 603 was used to correct for variability between samples for both APCI-QTOF-MS and GC-NCI-MS methods. For blank control, one procedural blank was included in every five samples to monitor background level. Isotopically labeled standard was spiked in every sample to account for the processing loss and matrix effects. Spiking experiments $(n=3)$ of $1 \mu \mathrm{g}$ SCCPs $(63.0 \% \mathrm{Cl})$ and $2 \mu \mathrm{g}$ MCCPs $(57.0 \% \mathrm{Cl})$ showed satisfactory percent recovery of $93 \pm 15 \%$ (mean \pm RSD) and $86 \pm 15 \%$, respectively. Limits of detection and limits of quantification (LODs and LOQs, respectively) for SCCPs, MCCPs, and LCCPs were calculated as average blank level $(n=9)$ plus three or ten times the standard deviation of the blank (SD), respectively (Table S5). The recoveries of isotopically labeled standards $\left({ }^{13} \mathrm{C}-\mathrm{HCD}\right)$ were $104 \pm 13 \%$ in all samples.

Physiological Parameters. The hepatosomatic index (HSI) was defined as the ratio of liver weight to body weight for frog individuals. The ratios of egg to liver $(E / L$ ratio) were calculated as the ratio of lipid-normalized concentrations of paired frog eggs and those of female frog livers. The log $K_{\text {ow }}$ values of CPs in the present study were estimated by the Moriguchi $\log \mathrm{P}(\mathrm{MLog} \mathrm{P})$ model $^{46,47}$ using an open source software VEGA. ${ }^{48}$ We assumed that no more than one chlorine atom was on any carbon. Modeling log $K_{\text {ow }}$ values of SCCPs and MCCPs reported by Glüge et al. ${ }^{49}$ were used to validate the model and has proven MLogP model generating good estimation for CPs. The $\log K_{\mathrm{ow}}$ values of CPs congener groups are summarized in Table $\mathrm{S} 6$.

Statistical Analysis. Data in the range between LOD and LOQ were substituted with the value of $\mathrm{LOQ} / \sqrt{2}$ for statistical analysis. Statistical analysis was performed using SPSS Statistics 23 (IBM Corp.). The significance level was set at $5 \%$ (i.e., $\alpha=0.05$ ). CP concentrations, and $E / L$ ratios were non-normally distributed (Kolmogorov-Smirnov test), and hence were subjected to logarithmic transformations prior to further processing. The independent samples $t$ test was used to compare means between two groups. Correlation analysis was conducted to explore the relationship between CPs level and carbon/chlorine number or $\log K_{\text {ow }}$ value.

\section{RESULTS AND DISCUSSION}

Occurrence of SCCPs, MCCPs, and LCCPs in Different Frog Tissues. The CP concentrations in frog liver, muscle, and egg samples are presented in Table 1. High detection frequencies were found for SCCPs (97\%), MCCPs (100\%), and LCCPs $(85 \%)$ in all frog samples. The total CP concentrations in frog liver, muscle, and egg samples were in the range of $35-1200,6.3-97$, and $6.8-300 \mathrm{ng} / \mathrm{g} \mathrm{ww}$, respectively. In both frog liver and egg samples, the concentrations decreased in the order of SCCPs > MCCPs $>$ LCCPs, contributing to $79 \%, 18 \%$, and $3 \%$ of the total CPs levels, respectively. However, MCCPs were the dominant CP groups (43\%) followed by SCCPs (41\%) and LCCPs (16\%) in the pooled muscle samples. The high proportion of SCCPs found in frog samples suggested their great bioaccumulation potentials. Meanwhile, bioavailability of medium- and longchain CP groups in amphibians should not be overlooked given their high detection frequencies.

To date, studies on CP level in frog remain scarce. Gao et al. ${ }^{30}$ reported the SCCP concentrations of a frog sample to be $4490 \mathrm{ng} / \mathrm{g} \mathrm{dw}$, higher than our results (20-180 ng/g dw), but they did not provide the information on frog species, tissue name, or sampling area. Compared with its vertebrate relatives fish, the CPs levels in frog samples (Table 1, SCCPs ND-9200 $\mathrm{ng} / \mathrm{g} \mathrm{lw}, \mathrm{MCCPs}<$ LOQ-1800 ng/g lw) in the present study were higher than those in freshwater top predatory fish (mean value: SCCPs 2-8 ng/g ww, MCCPs 1-12 ng/g ww) from Canada $^{7}$ and cod liver (SCCPs 19-143 ng/g ww, MCCPs 25-106 ng/g ww) from Baltic Sea, ${ }^{21}$ but lower than or comparable to CP levels in freshwater fish (mean value: SCCPs $11000-25000 \mathrm{ng} / \mathrm{g} \mathrm{lw}$ ) from a effluent-receiving freshwater lake in China ${ }^{26}$ and marine fish (mean value: SCCPs 622-1220 ng/g lw, MCCPs 1000-3800 ng/g lw) from South China Sea. ${ }^{10}$ Our previous research investigated the occurrence of SCCPs, MCCPs, and LCCPs in the muscle of bird, reptile, fish, and mammal species in the same sampling area. $^{25}$ The CPs levels in frog muscle samples observed herein were much lower than those in reptile and mammal species, but rivalling or higher than those in fish and bird species from the YRD. Frogs exhibiting similar CPs levels with fish and bird species may be due to their alike habitats and food items such as insects. Higher levels in reptile and mammal species than frogs may indicate biomagnification of CPs in food chains, but in-depth studies of more specific predator-prey systems are needed.

The frog liver samples contained significantly higher CP levels than the eggs and muscle samples (Table $1, p<0.01$ ). Similar concentration relationships between liver and muscle tissues were also found for SCCPs in snakehead and mud carp, ${ }^{50}$ PBDEs in rice frogs, ${ }^{36}$ and polyfluoroalkyl substances in black-spotted frogs. ${ }^{51}$ Like other vertebrates, the liver of amphibians performs the functions including energy and protein metabolism, biotransformation, and detoxification. Additionally, temperate amphibians store large amounts of glycogen and fat in liver in the autumn as energy sources for hibernation. ${ }^{52}$ The lipid content of liver tissues (22.63 \pm $8.18 \%)$ was much higher than that of muscle $(0.56 \pm 0.06 \%)$ and egg tissues $(9.87 \pm 2.26 \%)$. Moreover, no significant differences were found among lipid normalized concentrations of liver, muscle, and egg tissues $(p>0.05)$. Therefore, the higher accumulation of CPs in liver may be driven by the lipid enrichment and/or hepatic sequestration caused by the induction of hepatic microsomal binding proteins. ${ }^{53}$

CP Congener Group Patterns in Different Frog Tissues. The patterns of $\mathrm{CP}$ congener groups $\left(\mathrm{C}_{10-11} \mathrm{Cl}_{3-12}\right.$, $\left.\mathrm{C}_{12-26} \mathrm{Cl}_{2-12}\right)$ and those of carbon and chlorine in frog samples are provided in Figures 1 and S2. In most frog samples, the SCCP alkane chain-length group patterns were dominated by 

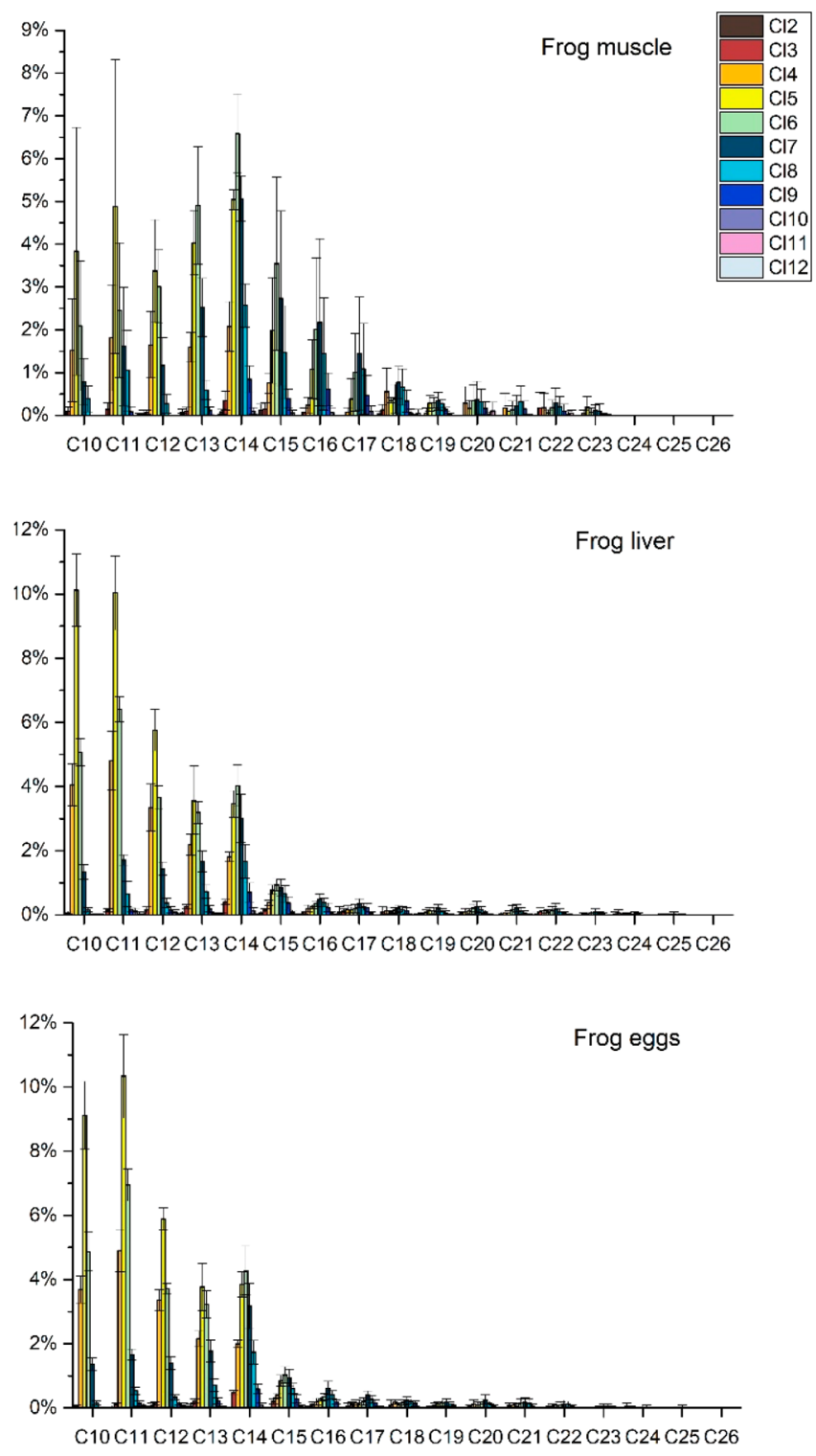

Figure 1. Congener group pattern of chlorinated paraffins (CPs, $\mathrm{C}_{10-11} \mathrm{Cl}_{3-12}, \mathrm{C}_{12-26} \mathrm{Cl}_{2-12}$ in muscle, liver, and egg of black-spotted frogs from Yangtze River Delta (YRD). All the vertical axis represent percent relative abundance.

$\mathrm{C}_{11}(33.9 \%)$ followed by $\mathrm{C}_{10}(28.4 \%)$. The exception was for the pooled muscle samples $(n=5)$ in which the dominant SCCPs group was $\mathrm{C}_{13}(31.4 \%)$ followed by $\mathrm{C}_{11}(27.2 \%)$. Similar patterns dominated by $\mathrm{C}_{11}$ were also found in Chinese softshell turtle from Gaobeidian Lake, China, ${ }^{26}$ marine food web from Bohai Sea, China, ${ }^{11}$ and Greenland shark from Iceland. ${ }^{54}$ Among MCCPs, $\mathrm{C}_{14}$ was the most abundant alkane chain-length group in all samples contributing to $63.9 \%$ of MCCPs, followed by $\mathrm{C}_{15}(19.0 \%)$. The LCCPs alkane chainlength groups was dominated by $\mathrm{C}_{18}(23.6 \%)$ followed by $\mathrm{C}_{20}$ (20.4\%). The alkane chain-length group patterns for MCCPs and LCCPs were consistent with observations from previous studies on various biotic and abiotic matrices.,10,55,56 The dominance of $\mathrm{C}_{14}$ and $\mathrm{C}_{18}$ for MCCPs and LCCPs may be due to the prevalence of these two groups in $\mathrm{CP}$ commercial products manufactured and/or used in China. ${ }^{25}$ In addition, $\mathrm{C}_{14}$ and $\mathrm{C}_{18}$ have shorter carbon chain length and smaller molecular size among MCCPs and LCCPs groups, resulting in higher bioavailability potentials. ${ }^{57}$ With regards to chlorine patterns of $\mathrm{CPs}$ (Figure S2), $\mathrm{Cl}_{5}$ was predominant in most species (31.9\% of CPs), followed by $\mathrm{Cl}_{6}(25.8 \%)$ and $\mathrm{Cl}_{4}$ (15.4\%), while $\mathrm{Cl}_{6}$, with a contribution of $27.0 \%$ to total $\mathrm{CPs}$, dominated over other chlorine groups in the muscle samples. The chlorine pattern dominated by $\mathrm{Cl}_{5-6}$ was also observed in marine food web from South China Sea. ${ }^{10}$

Our previous study reported different $\mathrm{CP}$ congener patterns in muscle samples of assorted vertebrate species in YRD, which was considered largely driven by habitats and feeding habits. ${ }^{10}$ By comparison, the $\mathrm{CP}$ congener group patterns of frog muscles in this study were similar to those of collared scops owl and common cuckoo. These two bird species mainly prey on insects, overlapping the major food items of frogs. Therefore, the similar patterns and close CP levels between frogs and these two bird species may result from their similar food sources.

The frog liver and frog egg samples shared close CPs congener group patterns while pooled muscle samples had different ones (Figure 1). Frog liver and egg samples were enriched in short chain CPs groups $\left(\mathrm{C}_{10-11}\right)$, but frog muscle samples tend to have higher proportions of long chain groups $\left(\mathrm{C}_{13-14}\right)$. To date, very few data are available on the relationship on muscle- and liver-associated $\mathrm{CP}$ concentrations. Sun et al. investigated the tissue distribution of SCCPs in two freshwater fish species, and found that liver preferentially accumulated high lipophilic chemicals compared to other tissues. ${ }^{50}$ However, therein only SCCPs $\left(\mathrm{C}_{10-13} \mathrm{Cl}_{5-10}\right)$ were investigated for the tissue-specific accumulation. Additionally, the frog liver functions as storage of glycogen and fat to a greater extent ${ }^{52}$ which might lead to enhanced POPs load and different contaminant patterns. Frog liver and egg samples shared similar CP congener patterns which might because the yolk of frog eggs was produced in the liver of maternal frogs. ${ }^{52}$ The relationship between maternal frog liver and paired eggs will be further discussed in the maternal transfer section below.

Relationships between CPs Burdens in Liver and Physiological Parameters Suggested Liver Metabolism. The hepatosomatic index (HSI) has been used as an estimate of energy status ${ }^{58}$ as well as biomarkers for contaminant exposure. ${ }^{59}$ Since liver is an important organ mainly responsible for detoxification and energy storage, HSI could reflect the overall health condition of organisms. In the present study, significant negative correlation was found between HSI and total CP levels in frog livers (Figure S3, R $=0.620, p<$ 0.005). Similar decreasing trends of HSI were also observed for fish after exposure to cadmium and zinc. ${ }^{60,61}$ The negative correlation indicated that the frog individuals with higher CPs exposure tended to have downsized liver tissues. Since elimination of contaminants need extra energy, the small hepatic tissue may be due to the reduction of hepatic glycogen deposits which has been observed in estrogen-treated carp and flounder. ${ }^{62,63}$ Our results suggested that high $\mathrm{CP}$ exposure may reduce the energy storage in frog liver, further leading to a lower survival rate of frogs during their hibernation.

The total CP levels in frog liver samples were negatively correlated with body weight (Figure S3, $\mathrm{R}=0.632, p<0.005$ ) and SVL (Figure S3, R $=0.679, p<0.001$ ). The negative correlation between body size and CP levels was in line with those in tapertail anchovy and Bombay ducks in Pearl River Estuary. ${ }^{22}$ Moreover, significant positive correlations were found between HSI and SVL as well as between HSI and body weight $(p<0.05)$, indicating the negative correlations between 
CP levels and body weight (SVL) may also be caused by the reduction of energy storage in body. To some extent body weight and SVL represent the body condition and fat content of wildlife.

No significant relationships were found between total CPs levels and lipid contents (Figure S3), which was inconsistent with previous studies. ${ }^{22,23,36,50} \mathrm{CPs}$ are a group of lipophilic compounds and their partitioning in organisms generally follows the lipid distribution like other POPs. The lack of significance between lipid content and CP levels indicated that other factors (e.g., bioaccumulation pathway and metabolism) besides lipid content influenced liver CP deposition in frogs.

Sexual Difference of CP Accumulation and Maternal Transfer. No significant differences in hepatic SCCPs, MCCPs, and LCCPs levels were observed between male and female frogs (Table $1, p>0.05$ ). However, for the pooled muscle samples, the mean concentrations of SCCPs, MCCPs, and LCCPs in the males were 23, 38, and $12 \mathrm{ng} / \mathrm{g}$ ww, respectively, which were 3.3-7.6 times higher than those in the females. Similar sexual differences in frog species have also been observed for OCPs, PCDD/Fs, coplanar PCBs, ${ }^{35}$ and novel and legacy perfluoroalkyl substances. ${ }^{51}$ The maternal transfer of contaminants from female frog to egg was possibly responsible for the lower CP concentrations in female muscle. The lack of sexual-differences in CP levels found in frog liver tissues might be attributed to several other factors such as the higher metabolic capacity of male frogs. ${ }^{36}$ Regarding CP congener patterns, the frogs' liver tissues exhibited similar patterns while the muscle tissues of male and female frogs showed different CP congener patterns (Figure S4). The female frog muscles were enriched in short chain CPs groups $\left(\mathrm{C}_{10-12}\right)$ while male frog muscles tended to accumulate a higher proportion of long chain CPs groups $\left(\mathrm{C}_{13-17}\right)$. To date, little research has studied the sexual difference of CPs in biotas. Zeng et al. $^{27}$ found no significantly gender-associated differences of SCCPs and MCCPs in cetacean species. The sexrelated discrepancies in $\mathrm{CP}$ congener group patterns were not well-documented so far, but several factors, e.g., maternal transfer, breeding activity, and metabolic capacity/rate may be the causes. Further research on the sex-related differences for CP accumulations in wildlife would be required.

Most of the CP congener groups (171 of 185, 92.4\%) detected in female liver tissues were also detected in the paired eggs (Figure 1), highlighting the maternal transfer of CPs in frogs. In female frogs, liver is the chamber to produce vitellogenin, a precursor protein of egg yolk. ${ }^{52}$ Therefore, the $\mathrm{CP}$ concentration ratio of eggs to the paired maternal liver (E/ $L$ ratio) was used to evaluate the extent to which CPs were subjected to maternal transfer in frogs. The $E / L$ ratios of SCCPs, MCCPs, and LCCPs for black-spotted frogs ranged of $0.086-1.0,0.077-0.83$, and $0.14-1.6$, respectively. Comparable results were observed for PBDEs $(0.29-1.35)$ in rice frog ${ }^{36}$ as well as OCPs and PCBs $(0.39-1.1)$ in Japanese brown frog. ${ }^{35}$ Among three CPs groups, LCCPs had the highest mean $E / L$ ratio (0.71) followed by MCCPs (0.52) and SCCPs (0.35). It is noteworthy that long chain CPs were more easily transferred to the next generation.

A positive linear correlation was found between $E / L$ ratios and carbon atoms numbers of CP congener groups (Figure S5, $\mathrm{R}=0.362, p<0.001)$. The $E / L$ ratio gained with the increased carbon atoms number especially for $C_{10-20}$. The $E / L$ ratios of $\mathrm{C}_{21-25}$ were largely scattered and thus it is difficult to address the exact trend of $E / L$ ratio for $C_{21-25}$. The positive trend agree well with a recent study on placental transfer of SCCPs and MCCPs in humans. ${ }^{64}$ The cord to maternal serum ratios of CPs $\left(\mathrm{C}_{10-16}\right)$ was generally increased with the length of carbon chain. The higher ratios observed for longer chain CP congener groups may be due to their high $K_{\text {ow }}$ values which lead to their greater affinities to the lipoproteins. A general parabolic relationship was observed between $E / L$ ratio and chlorine number (Figure S5, R $=0.326, p<0.001$ ). The breakpoint from positive to negative trend was approximately $\mathrm{Cl}_{6-7}$. This observation was consistent with study of PBDEs in rice frogs where the relationship between bromine atoms and $\mathrm{E} / \mathrm{L}$ ratio demonstrated a clear parabolic trend. ${ }^{36}$

The relationship between $E / L$ ratio and $\log K_{\text {ow }}$ of CPs congener groups were further investigated (Figure 2). A

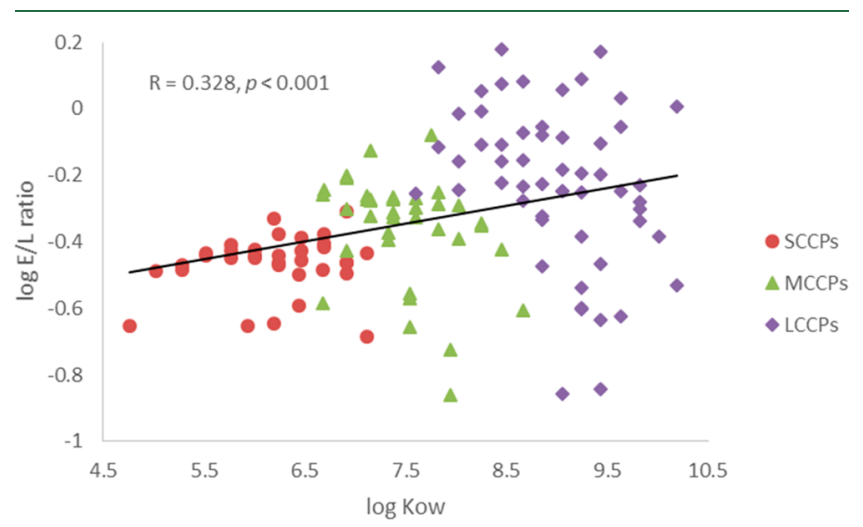

Figure 2. Relationship between $E / L$ ratio and octanol-water partitioning coefficients ( $\log K_{\text {ow }}$ ) of SCCPs, MCCPs, and LCCPs congener groups.

significant positive linear correlation was found between $E / L$ ratio and $\log K_{\mathrm{ow}}$ (Figure $2, \mathrm{R}=0.328, p<0.001$ ). In general, $E / L$ ratios of $C P$ congener groups tend to raise with increasing $\log K_{\text {ow }}$ values. Similarly, a positive trend was observed in zebrafish exposed to PBDEs, which showed high $E / L$ ratios for congeners with larger $\log K_{\text {ow }}{ }^{65}$ However, a significantly negative correlation was found for PCDD/Fs in frogs. ${ }^{35}$ In the process of yolk deposition in oocytes, lipophilic contaminants bind to the different lipoproteins including very low-density lipoproteins and high-density ones (such as vitellogenin), and then transport from maternal liver to eggs. ${ }^{65}$ Therefore, the affinity and selectivity of lipoproteins might play an important role in determining the maternal transfer ratios of contaminants. Our results clearly indicated the transport of CPs from maternal frog to egg was related to the lipophilicity of the chemicals. CPs congener groups with higher $\log K_{\text {ow }}$ such as LCCPs have elevated affinity to the lipoproteins, and thus are more likely to transport into the eggs, making maternal transfer a vital exposure pathway of frog embryos to chlorinated paraffins, particularly LCCPs.

Environmental Implications. A long period of time would be taken for the complete elimination of SCCPs, while increasing production and usage of their alternatives (e.g., MCCPs and LCCPs) have been confirmed by recent studies surveying CPs in several environmental matrices. ${ }^{12,27,66,67}$ Our work investigated the tissue-specific deposition of SCCPs, MCCPs, and LCCPs in frogs, indicating their considerable bioavailability and bioaccumulation in amphibians. Different $\mathrm{CP}$ levels and congener group patterns were found among frog tissues and between two genders, probably driven by several 
complex factors. Further research on the tissue distribution and sex-related accumulations of CPs in wildlife would be necessary. The relationship between HSI and CP levels suggested that high $\mathrm{CP}$ exposure may cause reduction of energy storage in frog liver, posing ecological risks to frogs. Finally, we confirmed the maternal transfer of SCCPs, MCCPs, and LCCPs in frogs for the first time and highlighted the fact that maternal transfer is a particularly important uptake pathway of longer chain CPs (e.g., LCCPs) for developing embryos. Further research on amphibian embryotic toxicity of longer chain CPs is urgently needed since longer chain CPs groups, which is still in high-volume use, are favored by the maternal transfer, and may consequently cause adverse effects on amphibians at their early life stage.

\section{ASSOCIATED CONTENT}

\section{S Supporting Information}

The Supporting Information is available free of charge on the ACS Publications website at DOI: 10.1021/acs.est.8b06350.

CP technical product list (Table S1); pattern-deconvolution results (Tables S2-S4, Figure S1); LOQ (Table S5); $\log K_{\mathrm{ow}}$ values (Table S6); carbon, chlorine, and gender-associated group patterns (Figures S2 and S4); relationships of $\log \mathrm{CP}$ levels with physiological parameters (Figure S3); and relationships of $\log E / L$ ratio with carbon and chlorine numbers (Figure S5) (PDF)

\section{AUTHOR INFORMATION}

\section{Corresponding Author}

*E-mail: capitalzyh@yahoo.com.

ORCID

Bo Yuan: 0000-0002-2043-8128

Yihui Zhou: 0000-0002-2219-1771

Ziye Zheng: 0000-0002-7898-341X

Yan Wu: 0000-0001-7876-261X

\section{Author Contributions}

${ }^{\#}$ These authors contributed equally to this research.

\section{Notes}

The authors declare no competing financial interest.

\section{ACKNOWLEDGMENTS}

The study was financially supported by the National Natural Science Foundation of China (Grant No. 41401571, 21876136), and the Swedish Research Council (No. 6392013-6913).

\section{REFERENCES}

(1) Bayen, S.; Obbard, J. P.; Thomas, G. O. Chlorinated paraffins: a review of analysis and environmental occurrence. Environ. Int. 2006, 32 (7), 915-29.

(2) Feo, M. L.; Eljarrat, E.; Barceló, D.; Barceló, D. Occurrence, fate and analysis of polychlorinated n-alkanes in the environment. $\operatorname{Tr} A C$, Trends Anal. Chem. 2009, 28 (6), 778-791.

(3) Tomy, G. T.; Fisk, A. T.; Westmore, J. B.; Muir, D. C. Environmental chemistry and toxicology of polychlorinated n-alkanes. Rev. Environ. Contam. Toxicol. 1998, 158 (158), 53-128.

(4) Fiedler, H. Short-Chain Chlorinated Paraffins: Production, Use and International Regulations.; Springer: Berlin/Heidelberg, 2010; pp 140.

(5) Chen, M. Y.; Luo, X. J.; Zhang, X. L.; He, M. J.; Chen, S. J.; Mai, B. X. Chlorinated paraffins in sediments from the Pearl River Delta,
South China: spatial and temporal distributions and implication for processes. Environ. Sci. Technol. 2011, 45 (23), 9936-43.

(6) Li, Q.; Li, J.; Wang, Y.; Xu, Y.; Pan, X.; Zhang, G.; Luo, C.; Kobara, Y.; Nam, J. J.; Jones, K. C. Atmospheric short-chain chlorinated paraffins in China, Japan, and South Korea. Environ. Sci. Technol. 2012, 46 (21), 11948-54.

(7) Saborido Basconcillo, L.; Backus, S. M.; McGoldrick, D. J.; Zaruk, D.; Sverko, E.; Muir, D. C. Current status of short- and medium chain polychlorinated $\mathrm{n}$-alkanes in top predatory fish across Canada. Chemosphere 2015, 127, 93-100.

(8) Bogdal, C.; Niggeler, N.; Glüge, J.; Diefenbacher, P. S.; Wächter, D.; Hungerbühler, K. Temporal trends of chlorinated paraffins and polychlorinated biphenyls in Swiss soils. Environ. Pollut. 2017, 220, 891-899.

(9) Geng, N.; Zhang, H.; Zhang, B.; Wu, P.; Wang, F.; Yu, Z.; Chen, J. Effects of short-chain chlorinated paraffins exposure on the viability and metabolism of human hepatoma HepG2 cells. Environ. Sci. Technol. 2015, 49 (5), 3076-83.

(10) Zeng, L.; Lam, J. C. W.; Chen, H.; Du, B.; Leung, K. M. Y.; Lam, P. K. S. Tracking Dietary Sources of Short- and Medium-Chain Chlorinated Paraffins in Marine Mammals through a Subtropical Marine Food Web. Environ. Sci. Technol. 2017, 51 (17), 9543-9552.

(11) Ma, X.; Zhang, H.; Wang, Z.; Yao, Z.; Chen, J.; Chen, J. Bioaccumulation and trophic transfer of short chain chlorinated paraffins in a marine food web from Liaodong Bay, North China. Environ. Sci. Technol. 2014, 48 (10), 5964-71.

(12) Wang, Y.; Li, J.; Cheng, Z.; Li, Q.; Pan, X.; Zhang, R.; Liu, D.; Luo, C.; Liu, X.; Katsoyiannis, A.; Zhang, G. Short- and mediumchain chlorinated paraffins in air and soil of subtropical terrestrial environment in the pearl river delta, South China: distribution, composition, atmospheric deposition fluxes, and environmental fate. Environ. Sci. Technol. 2013, 47 (6), 2679-87.

(13) Wu, J.; Gao, W.; Liang, Y.; Fu, J.; Gao, Y.; Wang, Y.; Jiang, G. Spatiotemporal Distribution and Alpine Behavior of Short Chain Chlorinated Paraffins in Air at Shergyla Mountain and Lhasa on the Tibetan Plateau of China. Environ. Sci. Technol. 2017, 51 (19), 11136-11144.

(14) UNEP, POPS/COP.8/CRP.13. Draft decision SC-8/[ ]: Shortchain chlorinated paraffins In 2017.

(15) Wang, Y.; Gao, W.; Jiang, G. Strengthening the Study on the Behavior and Transformation of Medium-Chain Chlorinated Paraffins in the Environment. Environ. Sci. Technol. 2017, 51 (18), 1028210283.

(16) UNEP, Short-Chain Chlorinated Paraffins (SCCPs): Draft risk risk management evaluation 2016.

(17) Castro, M.; Breitholtz, M.; Yuan, B.; Athanassiadis, I.; Asplund, L.; Sobek, A. Partitioning of Chlorinated Paraffins (CPs) to Daphnia magna Overlaps between Restricted and in-Use Categories. Environ. Sci. Technol. 2018, 52 (17), 9713-9721.

(18) van Mourik, L. M.; Gaus, C.; Leonards, P. E.; de Boer, J. Chlorinated paraffins in the environment: A review on their production, fate, levels and trends between 2010 and 2015. Chemosphere 2016, 155, 415-28.

(19) Smalling, K. L.; Reeves, R.; Muths, E.; Vandever, M.; Battaglin, W. A.; Hladik, M. L.; Pierce, C. L. Pesticide concentrations in frog tissue and wetland habitats in a landscape dominated by agriculture. Sci. Total Environ. 2015, 502, 80-90.

(20) Sparling, D. W.; Linder, G.; Bishop, C. A.; Krest, S. Ecotoxicology of Amphibians and Reptiles; CRC Press: Boca Raton, FL, 2010.

(21) Reth, M.; Zencak, Z.; Oehme, M. First study of congener group patterns and concentrations of short- and medium-chain chlorinated paraffins in fish from the North and Baltic Sea. Chemosphere 2005, 58 (7), 847-54.

(22) Sun, R.; Luo, X.; Tang, B.; Li, Z.; Huang, L.; Wang, T.; Mai, B. Short-chain chlorinated paraffins in marine organisms from the Pearl River Estuary in South China: Residue levels and interspecies differences. Sci. Total Environ. 2016, 553, 196-203. 
(23) Luo, X. J.; Sun, Y. X.; Wu, J. P.; Chen, S. J.; Mai, B. X. Shortchain chlorinated paraffins in terrestrial bird species inhabiting an ewaste recycling site in South China. Environ. Pollut. 2015, 198, 41-6.

(24) Reth, M.; Ciric, A.; Christensen, G. N.; Heimstad, E. S.; Oehme, M. Short- and medium-chain chlorinated paraffins in biota from the European Arctic - differences in homologue group patterns. Sci. Total Environ. 2006, 367 (1), 252-60.

(25) Du, X. Y.; Yuan, B.; Zhou, Y.; Benskin, J. P.; Qiu, Y.; Yin, G.; Zhao, J. Short-, Medium-, and Long-Chain Chlorinated Paraffins in Wildlife from Paddy Fields in the Yangtze River Delta. Environ. Sci. Technol. 2018, 52 (3), 1072-1080.

(26) Zeng, L.; Wang, T.; Wang, P.; Liu, Q.; Han, S.; Yuan, B.; Zhu, N.; Wang, Y.; Jiang, G. Distribution and trophic transfer of shortchain chlorinated paraffins in an aquatic ecosystem receiving effluents from a sewage treatment plant. Environ. Sci. Technol. 2011, 45 (13), 5529-35.

(27) Zeng, L.; Lam, J. C.; Wang, Y.; Jiang, G.; Lam, P. K. Temporal Trends and Pattern Changes of Short- and Medium-Chain Chlorinated Paraffins in Marine Mammals from the South China Sea over the Past Decade. Environ. Sci. Technol. 2015, 49 (19), $11348-55$.

(28) Tomy, G. T.; Muir, D. C. G.; Stern, G. A.; Westmore, J. B. Levels of C10-C13Polychloro-n-Alkanes in Marine Mammals from the Arctic and the St. Lawrence River Estuary. Environ. Sci. Technol. 2000, 34 (9), 1615-1619.

(29) Letcher, R. J.; Morris, A. D.; Dyck, M.; Sverko, E.; Reiner, E. J.; Blair, D. A. D.; Chu, S. G.; Shen, L. Legacy and new halogenated persistent organic pollutants in polar bears from a contamination hotspot in the Arctic, Hudson Bay Canada. Sci. Total Environ. 2018, 610-611, 121-136.

(30) Gao, Y.; Zhang, H.; Zou, L.; Wu, P.; Yu, Z.; Lu, X.; Chen, J. Quantification of Short-Chain Chlorinated Paraffins by Deuterodechlorination Combined with Gas Chromatography-Mass Spectrometry. Environ. Sci. Technol. 2016, 50 (7), 3746-3753.

(31) Russell, R. W.; Gobas, F. A. P. C.; Haffner, G. D. Maternal transfer and in ovo exposure of organochlorines in oviparous organisms: A model and field verification. Environ. Sci. Technol. 1999, 33 (3), 416-420.

(32) Burýšková, B.; Bláha, L.; Vršková, D.; Šimková, K.; Maršálek, B. Sublethal Toxic Effects and Induction of gGutathione S-transferase by Short-Chain Chlorinated Paraffins (SCCPs) and C-12 alkane (dodecane) in Xenopus laevis Frog Embryos. Acta Veterinaria Brno. 2006, 75 (1), 115-122.

(33) Ren, X.; Zhang, H.; Geng, N.; Xing, L.; Zhao, Y.; Wang, F.; Chen, J. Developmental and metabolic responses of zebrafish (Danio rerio) embryos and larvae to short-chain chlorinated paraffins (SCCPs) exposure. Sci. Total Environ. 2018, 622-623, 214-221.

(34) Hopkins, W. A.; DuRant, S. E.; Staub, B. P.; Rowe, C. L.; Jackson, B. P. Reproduction, embryonic development, and maternal transfer of contaminants in the amphibian Gastrophryne carolinensis. Environ. Health Perspect. 2006, 114 (5), 661-6.

(35) Kadokami, K.; Takeishi, M.; Kuramoto, M.; Ono, Y. Maternal transfer of organochlorine pesticides, polychlorinated dibenzo-pdioxins, dibenzofurans, and coplanar polychlorinated biphenyls in frogs to their eggs. Chemosphere 2004, 57 (5), 383-389.

(36) Wu, J. P.; Luo, X. J.; Zhang, Y.; Chen, S. J.; Mai, B. X.; Guan, Y. T.; Yang, Z. Y. Residues of polybrominated diphenyl ethers in frogs (Rana limnocharis) from a contaminated site, South China: tissue distribution, biomagnification, and maternal transfer. Environ. Sci. Technol. 2009, 43 (14), 5212-7.

(37) Zhou, Y.; Asplund, L.; Yin, G.; Athanassiadis, I.; Wideqvist, U.; Bignert, A.; Qiu, Y.; Zhu, Z.; Zhao, J.; Bergman, A. Extensive organohalogen contamination in wildlife from a site in the Yangtze River Delta. Sci. Total Environ. 2016, 554-555, 320-8.

(38) Yuan, B.; Alsberg, T.; Bogdal, C.; MacLeod, M.; Berger, U.; Gao, W.; Wang, Y.; de Wit, C. A. Deconvolution of Soft Ionization Mass Spectra of Chlorinated Paraffins To Resolve Congener Groups. Anal. Chem. 2016, 88 (18), 8980-8.
(39) Yuan, B.; Bogdal, C.; Berger, U.; MacLeod, M.; Gebbink, W. A.; Alsberg, T.; de Wit, C. A. Quantifying Short-Chain Chlorinated Paraffin Congener Groups. Environ. Sci. Technol. 2017, 51 (18), 10633-10641.

(40) Zhou, Y.; Yin, G.; Du, X.; Xu, M.; Qiu, Y.; Ahlqvist, P.; Chen, Q.; Zhao, J. Short-chain chlorinated paraffins (SCCPs) in a freshwater food web from Dianshan Lake: Occurrence level, congener pattern and trophic transfer. Sci. Total Environ. 2018, 615, 1010-1018.

(41) Yuan, B.; Muir, D.; MacLeod, M. Methods for Trace Analysis of Short-, Medium-, and Long-chain Chlorinated Paraffins: Critical Review and Recommendations. Anal. Chim. Acta 2019 DOI: 10.1016/j.aca.2019.02.051.

(42) Yuan, B.; Strid, A.; Darnerud, P. O.; de Wit, C. A.; Nystrom, J.; Bergman, A. Chlorinated paraffins leaking from hand blenders can lead to significant human exposures. Environ. Int. 2017, 109, 73-80.

(43) Bogdal, C.; Alsberg, T.; Diefenbacher, P. S.; MacLeod, M.; Berger, U. Fast quantification of chlorinated paraffins in environmental samples by direct injection high-resolution mass spectrometry with pattern deconvolution. Anal. Chem. 2015, 87 (5), 2852-60.

(44) Brandsma, S. H.; van Mourik, L.; O’Brien, J. W.; Eaglesham, G.; Leonards, P. E.; de Boer, J.; Gallen, C.; Mueller, J.; Gaus, C.; Bogdal, C. Medium-Chain Chlorinated Paraffins (CPs) Dominate in Australian Sewage Sludge. Environ. Sci. Technol. 2017, 51 (6), 3364-3372.

(45) Yuan, B.; Strid, A.; Darnerud, P. O.; de Wit, C. A.; Nyström, J.; Bergman, A. Chlorinated paraffins leaking from hand blenders can lead to significant human exposures. Environ. Int. 2017, 109, 73-80.

(46) Moriguchi, I.; HIRONO, S.; LIU, Q.; NAKAGOME, I.; MATSUSHITA, Y. Simple method of calculating octanol/water partition coefficient. Chem. Pharm. Bull. 1992, 40 (1), 127-130.

(47) Moriguchi, I.; Hirono, S.; Nakagome, I.; Hirano, H. Comparison of reliability of $\log \mathrm{P}$ values for drugs calculated by several methods. Chem. Pharm. Bull. 1994, 42 (4), 976-978.

(48) Benfenati, E.; Manganaro, A.; Gini, G. C. In VEGA-QSAR: AI Inside a Platform for Predictive Toxicology, PAI@ AI* IA, 2013; 2013; pp 21-28.

(49) Glüge, J.; Bogdal, C.; Scheringer, M.; Buser, A. M.; Hungerbühler, K. Calculation of Physicochemical Properties for Short- and Medium-Chain Chlorinated Paraffins. J. Phys. Chem. Ref. Data 2013, 42 (2), 023103.

(50) Sun, R.; Luo, X.; Tang, B.; Chen, L.; Liu, Y.; Mai, B. Bioaccumulation of short chain chlorinated paraffins in a typical freshwater food web contaminated by e-waste in south china: Bioaccumulation factors, tissue distribution, and trophic transfer. Environ. Pollut. 2017, 222, 165-174.

(51) Cui, Q.; Pan, Y.; Zhang, H.; Sheng, N.; Wang, J.; Guo, Y.; Dai, J. Occurrence and Tissue Distribution of Novel Perfluoroether Carboxylic and Sulfonic Acids and Legacy Per/Polyfluoroalkyl Substances in Black-Spotted Frog (Pelophylax nigromaculatus). Environ. Sci. Technol. 2018, 52 (3), 982-990.

(52) Crawshaw, G. J.; Weinkle, T. K. Clinical and pathological aspects of the amphibian liver. In Seminars in Avian and Exotic Pet Medicine; Elsevier: 2000; pp 165-173.

(53) Kubota, A.; Iwata, H.; Tanabe, S.; Yoneda, K.; Tobata, S. Levels and toxicokinetic behaviors of PCDD, PCDF, and coplanar PCB congeners in common cormorants from Lake Biwa, Japan. Environ. Sci. Technol. 2004, 38 (14), 3853-9.

(54) Strid, A.; Bruhn, C.; Sverko, E.; Svavarsson, J.; Tomy, G.; Bergman, A. Brominated and chlorinated flame retardants in liver of Greenland shark (Somniosus microcephalus). Chemosphere 2013, 91 (2), 222-8.

(55) Wong, F.; Suzuki, G.; Michinaka, C.; Yuan, B.; Takigami, H.; de Wit, C. A. Dioxin-like activities, halogenated flame retardants, organophosphate esters and chlorinated paraffins in dust from Australia, the United Kingdom, Canada, Sweden and China. Chemosphere 2017, 168, 1248-1256.

(56) Li, T.; Wan, Y.; Gao, S.; Wang, B.; Hu, J. High-Throughput Determination and Characterization of Short-, Medium-, and Long- 
Chain Chlorinated Paraffins in Human Blood. Environ. Sci. Technol. 2017, 51 (6), 3346-3354.

(57) Gluge, J.; Schinkel, L.; Hungerbuhler, K.; Cariou, R.; Bogdal, C. Environmental Risks of Medium-Chain Chlorinated Paraffins (MCCPs): A Review. Environ. Sci. Technol. 2018, 52 (12), 67436760.

(58) Chellappa, S.; Huntingford, F.; Strang, R.; Thomson, R. Condition factor and hepatosomatic index as estimates of energy status in male three-spined stickleback. J. Fish Biol. 1995, 47 (5), $775-787$.

(59) Facey, D. E.; Blazer, V. S.; Gasper, M. M.; Turcotte, C. L. Using fish biomarkers to monitor improvements in environmental quality. J. Aquat. Anim. Health 2005, 17 (3), 263-266.

(60) Pereira, J. J.; Mercaldoallen, R.; Kuropat, C.; Luedke, D.; Sennefelder, G. Effect of Cadmium Accumulation on Serum Vitellogenin Levels and Hepatosomatic and Gonadosomatic Indexes of Winter Flounder (Pleuronectes-Americanus). Arch. Environ. Contam. Toxicol. 1993, 24 (4), 427-431.

(61) Zheng, J. L.; Luo, Z.; Liu, C. X.; Chen, Q. L.; Tan, X. Y.; Zhu, Q. L.; Gong, Y. Differential effects of acute and chronic zinc $(\mathrm{Zn})$ exposure on hepatic lipid deposition and metabolism in yellow catfish Pelteobagrus fulvidraco. Aquat. Toxicol. 2013, 132-133, 173-81.

(62) Schwaiger, J.; Spieser, O. H.; Bauer, C.; Ferling, H.; Mallow, U.; Kalbfus, W.; Negele, R. D. Chronic toxicity of nonylphenol and ethinylestradiol: haematological and histopathological effects in juvenile Common carp (Cyprinus carpio). Aquat. Toxicol. 2000, 51 (1), 69-78.

(63) Zaroogian, G.; Gardner, G.; Horowitz, D. B.; Gutjahr-Gobell, R.; Haebler, R.; Mills, L. Effect of $17 \beta$-estradiol, o, p'-DDT, octylphenol and p, p'-DDE on gonadal development and liver and kidney pathology in juvenile male summer flounder (Paralichthys dentatus). Aquat. Toxicol. 2001, 54 (1-2), 101-112.

(64) Qiao, L.; Gao, L.; Zheng, M.; Xia, D.; Li, J.; Zhang, L.; Wu, Y.; Wang, R.; Cui, L.; Xu, C. Mass Fractions, Congener Group Patterns, and Placental Transfer of Short- and Medium-Chain Chlorinated Paraffins in Paired Maternal and Cord Serum. Environ. Sci. Technol. 2018, 52 (17), 10097-10103.

(65) Nyholm, J. R.; Norman, A.; Norrgren, L.; Haglund, P.; Andersson, P. L. Maternal transfer of brominated flame retardants in zebrafish (Danio rerio). Chemosphere 2008, 73 (2), 203-8.

(66) Yuan, B.; Brüchert, V.; Sobek, A.; de Wit, C. A. Temporal Trends of C8-C36 Chlorinated Paraffins in Swedish Coastal Sediment Cores over the Past 80 Years. Environ. Sci. Technol. 2017, 51 (24), 14199-14208.

(67) Yuan, B.; Vorkamp, K.; Roos, A. M.; Faxneld, S.; Sonne, C.; Garbus, S. E.; Lind, Y.; Eulaers, I.; Hellstrom, P.; Dietz, R.; Persson, S.; Bossi, R.; de Wit, C. A.. Accumulation of Short-, Medium-, and Long-Chain Chlorinated Paraffins in Marine and Terrestrial Animals from Scandinavia Environ. Sci. Technol. 2019.533526 